\title{
The Effect of Increasing Chemical Complexity on the Mechanical and Functional Behavior of NiTi-Related Shape Memory Alloys
}

\author{
Christian Hinte $^{1} \cdot$ Khemais Barienti $^{1} \cdot$ Jan Steinbrücker $^{1} \cdot$ Jana-Mercedes Hartmann $^{1}$. \\ Gregory Gerstein $^{1}$ (D) $\cdot$ Sebastian Herbst ${ }^{1} \cdot$ David Piorunek $^{2} \cdot$ Jan Frenzel $^{2}$ • \\ Andrea Fantin $^{3,4} \cdot$ Hans Jürgen Maier ${ }^{1}$
}

Published online: 22 May 2020

(C) ASM International 2020

\begin{abstract}
The introduction of high-entropy alloys (HEA) into the field of shape memory alloys offers enormous potential for improving their functional properties. It is shown how a successive increase in chemical complexity results in strictly monotonically enlarged and increasingly distorted lattices. With increasing the number of elements added to the alloy, the effect of solid solution strengthening appears to be curtailed and first insights into the contribution of additional mechanisms based on lattice distortions are possible. The alloys developed in this study, reaching from ternary NiTiHf to senary TiZrHfCoNiCu, show a great potential to exploit interatomic interactions regarding improvement of functional fatigue. Despite the absence of stress plateaus related to detwinning, recovery
\end{abstract}

This invited article is part of a special issue of Shape Memory and Superelasticity to honor Prof. Dr.-Ing. Gunther Eggeler. This special issue was organized by Prof. Huseyin Sehitoglu, University of Illinois at Urbana-Champaign, and Prof. Dr.-Ing. Hans Jürgen Maier, Leibniz Universität Hannover.

Christian Hinte

hinte@iw.uni-hannover.de

Gregory Gerstein

gerstein@iw.uni-hannover.de

1 Leibniz Universität Hannover, Institut für Werkstoffkunde (Materials Science), An der Universität 2, 30823 Garbsen, Germany

2 Ruhr-Universität Bochum, Lehrstuhl Werkstoffwissenschaft, Universitätsstr. 150, 44780 Bochum, Germany

3 Technische Universität Berlin, Fachgebiet Struktur und Eigenschaften von Materialien, Hardenbergstr. 36, 10623 Berlin, Germany

4 Helmholtz-Zentrum Berlin, Institut für Angewandte Materialforschung, Hahn-Meitner-Platz 1, 14109 Berlin, Germany effects at loads above $1000 \mathrm{MPa}$ and significant strain recoveries are shown.

Keywords Mechanical behavior - NiTi - Compression tests - Functional degradation - X-ray diffraction (XRD) . High-entropy alloys (HEA) · Shape memory alloys (SMA)

\section{Introduction}

The technically most relevant shape memory alloys (SMAs), NiTi and its variants, are the only widely used SMAs. Their strain recovery of up to $8 \%$ for the one-way shape memory effect (SME) [1] can be exploited for many applications. Furthermore, it was shown that within the first SME cycles at $5 \%$ pseudoplastic strain up to $4.5 \%$ could be recovered [2]. However, SMAs suffer from functional degradation upon cyclic use of the shape memory effects [1, 3-5]. The functional degradation over subsequent cycles and the low transformation temperatures often hampers their use in the envisaged technical applications $[1,2,4,5]$. Hence, the key objectives of the development of SMAs is to increase fatigue resistance and operating temperatures.

The development of high-entropy alloys (HEAs) is a relatively young field in materials science. HEAs are defined as single-phase metals with at least five main elements with $>5$ at $\%$ each and equimolar or near-equimolar stoichiometry $[6,7]$. The absence of a main element is a crucial feature of these alloys and is reported to lead to a demonstrably strong change in material behavior and deformation mechanisms [7-9]. The most studied materials in the field of HEAs are the Cantor alloy (CrMnFeCoNi) [10], the Senkov alloy (TiZrHfNbTa) [11] and their modifications $[6,8,12]$. Criteria such as valence electron 
concentration and mass variance play a decisive role in the selection of the elements of a HEA [7]. Since HEAs are classified as single-phase materials, the alloying elements must be completely soluble in each other. This requires substitution with elements that are neighboring in the periodic table or have similar characteristics to the element to be replaced. In the Cantor alloy, $\mathrm{Fe}, \mathrm{Cr}, \mathrm{Mn}, \mathrm{Co}$, and $\mathrm{Ni}$ have similar atomic radii and atomic masses, but significant differences in the number of valence electrons. In this case, the substitution of elements occurs strictly within the period (see Fig. 1). In the case of the Senkov alloy, the substitution occurs mainly within two element groups. As a result, the increase in entropy is mainly realized by the mass variance and a predicted distortion of the crystal lattice [11].

Functional HEAs with martensitic transformation (MT) currently have a special status in the field of high-entropy research, leading to the new material class of high-entropy shape memory alloys (HESMAs). The development focusses on increasing the MT temperatures and the reversibility of the transformation. Canadinc et al. already achieved austenite finish temperatures exceeding $700{ }^{\circ} \mathrm{C}$ [13]. In their work the alloy development was based on binary $\mathrm{NiTi}$, the elements were almost exclusively varied with respect to atomic ratios, and substitution took place within each chemical group. The alloys investigated had astonishing material properties. However, $\mathrm{Ni}$ was substituted by high amounts of Pd. This makes a later technical use very expensive and reduces the field of application. For this reason, other research approaches such as the one by Firstov et al. employed $\mathrm{Co}$ and $\mathrm{Cu}$ as substitution elements $[5,6]$. Mechanical tests on HESMAs of the TiZrHfCoNiCu type have already been investigated by Chen et al. [14] and show both desired and undesired changes in properties compared to binary NiTi.

Alloys can be classified as low-, medium-, and highentropy alloys [6]. Medium-entropy alloys, which represent the transition region between low- and high-entropy, have three to four elements with equiatomic or near-equiatomic composition. Martensite-forming ternary systems such as CoNiGa have already shown very good shape memory properties $[15,16]$, despite the fact that they are by definition not high-entropy alloys [6]. Therefore, it is desirable to investigate both medium- and high-entropy systems $[7,8,10]$. To separate cause and effect of the entropic modification of alloys with respect to the change in material properties, it is necessary to show the path of a successive increase in chemical complexity (SICC).

The present study deals with the SICC of the already ternary alloy NiTiHf to the senary alloy TiZrHfCoNiCu. In contrast to other research approaches, the $\mathrm{Ti}$ is substituted within the chemical group by $\mathrm{Zr}$ and $\mathrm{Hf}$, whilst the $\mathrm{Ni}$ is replaced with its periodic neighbors by $\mathrm{Cu}$ and $\mathrm{Co}$. The phases formed, the transformation temperatures and the basic mechanical and functional properties are analyzed. The objective is to map the development of a possible alloy modification by successive increase in chemical complexity from ternary NiTiHf to senary TiZrHfCoNiCu. The characterization methods employed serve to understand the influence of additional elements on the material properties compared to a previous alloy with fewer elements and to gain insight into which mechanisms are responsible for the mechanical and functional properties. Furthermore, it will be investigated at which point the SICC has no further effect.

For this purpose, the changes of the phases due to the SICC were recorded and compared by X-ray diffraction (XRD) for as-cast and heat-treated conditions. The transition temperatures between martensite and austenite, which are of decisive importance for the functional properties, were determined by differential scanning calorimetry (DSC).

The effect of the SICC on the basic mechanical properties was determined by compression tests and compared
Fig. 1 Excerpt from the periodic table of elements; alloy systems investigated by the different research groups $[4,10,11,13]$ are highlighted by the respective color (Color figure online)

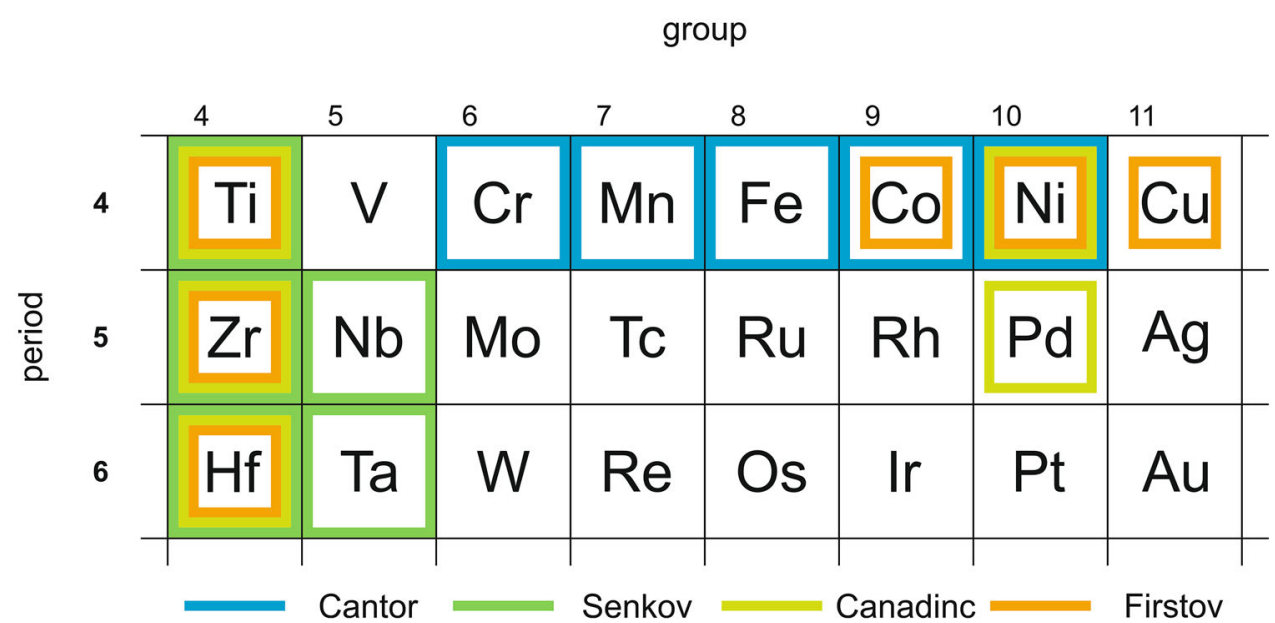


with already known literature values. Even though the compression tests do not show clear plateaus for detwinning of the martensite in the flow curves, reported e.g. in [17], a shape recovery could nevertheless be confirmed. Pseudoelasticity was assessed through other evaluation criteria, such as the rate of change of stress in the flow curve. Local plateaus or minima can indicate SMEs and provide guidelines for subsequent investigations.

\section{Methods and Materials}

The characterization of the forming phases was performed by X-ray diffraction (XRD) with a D8 Discover X-Ray diffractometer (Bruker) equipped with a 2D Vantec 500 detector and a $\mathrm{Ni}$ filter. The characteristic radiation lines used were $\mathrm{Cu} \mathrm{K} \alpha_{1}(1.5406 \AA)$ and $\mathrm{Cu} \mathrm{K} \alpha_{2}(1.5444 \AA)$. Measurements were taken on samples in as-cast and heattreated condition. Subsequently, lattice parameters on the heat-treated state were determined by Le Bail refinements $[18,19]$, using the TOPAS software [20].

The compression tests were performed on cylindrical samples with a height of $4 \mathrm{~mm}$ and a diameter of $2 \mathrm{~mm}$. For basic mechanical characterization, the specimens were tested at room temperature in a Z010 universal testing machine, regardless of their structural state (martensitic or austenitic). The functional properties were measured in a Z100 universal testing machine equipped with a tempering chamber. Test temperatures ranging from -80 to $250{ }^{\circ} \mathrm{C}$ were possible with this equipment. For analyzing the SE, stress-compression curves were recorded at different temperatures. For shape recovery, specimens in the martensitic state were compressed to a given stress value and then relieved. The resulting hystereses were recorded and the remaining specimen height after compression measured. The samples were then heated above the austenite finish temperature, $A_{\mathrm{f}}$, and the compression recovery was determined via the sample height.

The alloys used in this study are listed in Table 1 . The alloy compositions were extended from the ternary base alloy NiTiHf by adding elements up to senary systems. The

Table 1 Overview and nominal composition of investigated alloys in at. \% and the average metallic radius $r_{\text {calc }}$ in $\AA$ calculated by weighing the metallic radii [22] to the corresponding at. \%

\begin{tabular}{llllllll}
\hline Alloy & $\mathrm{Ni}$ & $\mathrm{Ti}$ & $\mathrm{Hf}$ & $\mathrm{Cu}$ & $\mathrm{Zr}$ & $\mathrm{Co}$ & $r_{\text {calc }}$ \\
\hline Tern (ternary) & 50 & 25 & 25 & & & & 1.385 \\
Quat (quaternary) & 25 & 25 & 25 & 25 & & & 1.395 \\
Quin (quinary) & 25 & 16.67 & 16.67 & 25 & 16.67 & & 1.407 \\
Co10Sen (senary) & 25 & 16.67 & 16.67 & 15 & 16.67 & 10 & 1.404 \\
Co12Sen (senary) & 18 & 16.67 & 16.67 & 20 & 16.67 & 12 & 1.406 \\
\hline
\end{tabular}

added elements are assigned either to the $\mathrm{Ni}$ equivalent or the Ti equivalent with reference to the stoichiometric ratio of NiTi [21]. The ratio of the equivalents remained unchanged during the alloy modification. The increasing chemical complexity is intended to provide information about the material behavior and the change in mechanisms when entropy is increased. In the field of senary materials, the stoichiometry of the Ni equivalent was varied while the element selection remained the same.

The materials were produced by arc melting and show a dendritic microstructure after casting [23, 24]. To investigate the influence of homogeneity, the alloys were additionally heat-treated at $900{ }^{\circ} \mathrm{C}$ for $100 \mathrm{~h}$ in an inert gas atmosphere and air cooled afterwards. After heat treatment, the samples were analyzed DSC to determine the martensite start and finish temperature $\left(M_{\mathrm{s}}, M_{\mathrm{f}}\right)$ as well as austenite-start and -finish temperatures $\left(A_{\mathrm{s}}, A_{\mathrm{f}}\right)$.

\section{Results and Discussion}

\section{Phase Characterization}

The X-ray diffractograms for the as-cast state and the associated heat-treated states are shown in Fig. 2. Two phases were identified according to the Le Bail refinements, the cubic austenitic B2 (spacegroup 221, Pm-3m, Fig. 2: black squares) and the monoclinic martensite B19' with main results reported in Table 2. A fit example is given in Appendix Fig. 8. Trials refining the B19' monoclinic cell using the spacegroup (SG) P2, P21, P21/c, Pc and $\mathrm{P} 21 / \mathrm{m}$ were carried out. No substantial differences were observed amongst the residuals, though in the P21, P21/c, and Pc cases a doubling of the cell in one direction was suggested by unit cell indexing. Finally, according to previous experimental and theoretical work on similar systems [13, 25] the $\mathrm{P} 21 / \mathrm{m}$ space group was selected (Fig. 2: open diamonds).

As shown in Table 2, SICC causes a gradual expansion for both phases, as could be inferred by the experimentally determined cell volume. This is expected, as from the NiTiHf ternary to the senary alloy, elements with higher nominal metallic radii were added in high enough concentrations (cf. Table 1) to increase the average metallic radius of the system, reported for comparison in Table 2.

From the quaternary alloy with SICC, the two phases are coexisting, though there is always a major contribution of one of the two: B2 in Quat or Co12Sen, and B19' in Quin or ColoSen. The quantification of the phases and the detailed structural analysis via Rietveld refinements are beyond the scope of the present study as the complexity of the monoclinic cell would require deeper crystallographic analysis based on measurements to be performed in a 


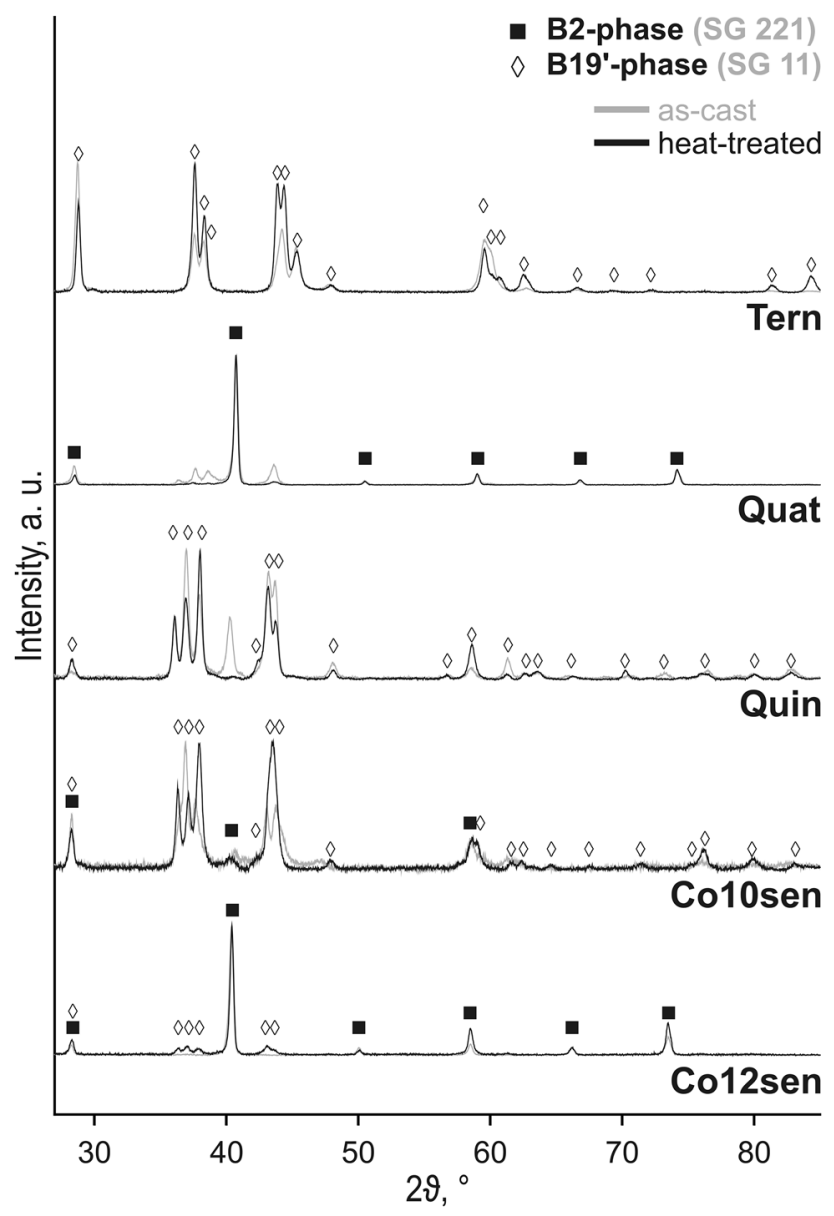

Fig. 2 Diffractograms of ternary to senary alloys in as-cast and heattreated state

synchrotron. Therefore, in Table 2 only the lattice parameters and the cell volume of the main phases are reported. Finally, the unit cell of the B19' phase seems to lessen its parameter $\beta$ with increasing chemical complexity and volume: no clear explanation is yet available, and more investigation on the crystallographic parameter $\beta$ is necessary.

A clear correlation between the phase type and the martensitic temperatures appears, with the $\mathrm{B} 19^{\prime}$ phase and the B2 phase showing higher and lower $M_{\mathrm{s}}$, respectively. While the difference in $M_{\mathrm{s}}$ temperatures of the B2 dominated alloys is in the same order of magnitude $(<60 \mathrm{~K})$, relevant $M_{\mathrm{s}}$ temperature differences are observed in the $\mathrm{B} 19^{\prime}$ dominated alloys, e.g., between Tern and Quin (above $200 \mathrm{~K}$ ). As can be inferred from Fig. 2, noticeable differences in the as-cast states appear between the Tern alloy (pure B19') and the Quin or Co12Sen (presence of some B2 phase), which is likely the explanation.

The necessity of a homogenizing heat treatment is given from the observed change in phase compositions. In case of the Quat alloy, it is apparent that in the as-cast state, small proportions of the martensitic B19' phase are also present in addition to the $\mathrm{B} 2$ main phase.

\section{Compression Tests}

The changes in mechanical properties during compression tests at room temperature (Fig. 3) caused by the SICC show a clear tendency. A comparison of the ultimate compressive strength (UCS) shows that alloy Tern has the highest UCS with an average of $2800 \mathrm{MPa}$. An increase in the number of elements leads to a decrease in the UCS. Quat, Quin, and Co10Sen have an almost equal UCS of $2400 \mathrm{MPa}$. Upon a comparison of the two senary materials Co10Sen and Co12Sen, which have the same element composition but different stoichiometries of the $\mathrm{Ni}$ equivalents, a difference of $8 \%$ in UCS is seen.

When comparing the fracture compression a similar tendency becomes obvious. The addition of further elements reduces the fracture compression to $21 \%$ for Co10Sen. As with the UCS, the fracture compression of Co12Sen increases by $5 \%$ compared to Co10Sen. This is a surprising observation from the standpoint of conventional alloy development with one primary element and several secondary elements. Despite the addition of further elements in high concentrations an expected solid solution strengthening [26] does not occur in the investigated alloys.

The heat treatment of the materials show only minor differences for Tern. Maximum strength, fracture compression, and the rate of change $\mathrm{d} \sigma / \mathrm{d} \varepsilon$ are almost identical. For the four-component Quat a difference can be seen. Although the heat-treated condition featured an UCS approx. $100 \mathrm{MPa}$ higher than the as-cast material, the fracture compression increased from 17 to $21 \%$.
Table 2 Lattice parameters in $\AA$ of the phases as determined by the Le Bail-refinement

\begin{tabular}{lccccccc}
\hline Alloy & B2 $a$ & Volume $\AA^{3}$ & \multicolumn{2}{l}{ B19' } & & Volume $\AA^{3}$ \\
\cline { 3 - 6 } & & & $A$ & $b$ & $c$ & $\beta$ & \\
\hline Tern & & & 3.088 & 4.086 & 4.941 & 104.2 & 60.43 \\
Quat & 3.126 & 30.55 & & & & & \\
Quin & & & 3.173 & 4.136 & 4.963 & 101.04 & 63.93 \\
Co10Sen & 3.154 & 31.37 & 3.144 & 4.149 & 4.948 & 102.16 & 63.10 \\
Co12Sen & 3.156 & 31.43 & 3.127 & 4.185 & 4.961 & 101.91 & 63.51 \\
\hline
\end{tabular}


Tern
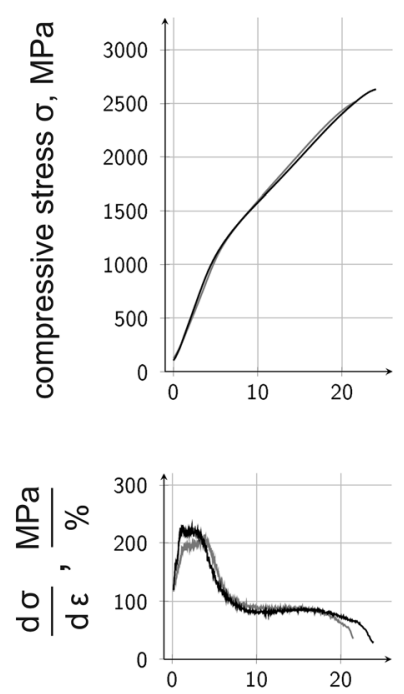

Quat
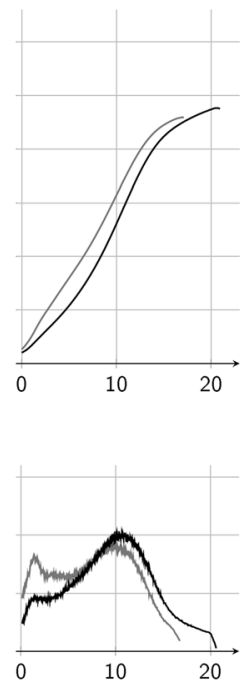

Quin
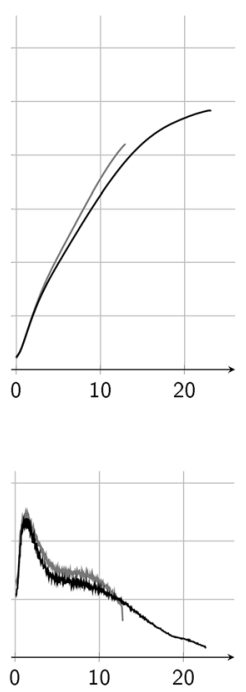

compression $\varepsilon$, \%
Co10Sen
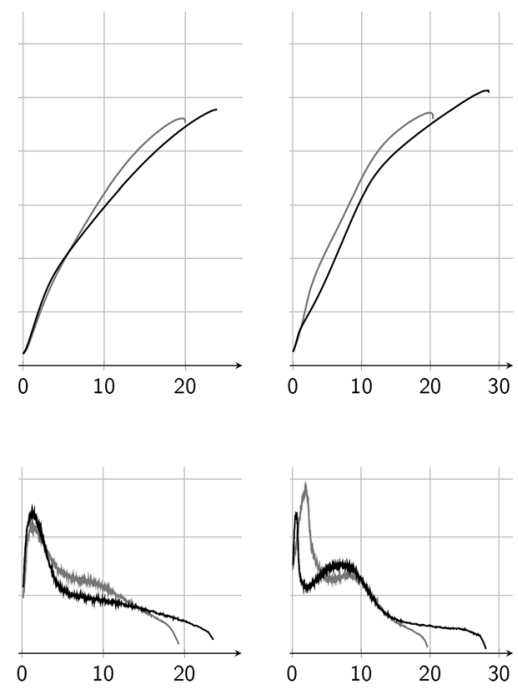

- as-cast

- heat treated

Fig. 3 Stress-compression curves and their evolution upon moving from ternary to senary materials in as-cast and in heat-treated conditions; see main text for details

The difference between the as-cast and heat-treated condition becomes even more pronounced for the Quin alloy. While the as-cast material featured $2100 \mathrm{MPa}$ UCS at $12 \%$ fracture compression, the heat-treated material achieved $2450 \mathrm{MPa}$ and $23 \%$ fracture compression. It is particularly noticeable that the heat treatment adds a significantly increased amount of plastic deformation after approx. $11 \%$ compression.

The heat treatment of the senary alloys Co10Sen and Co12Sen increased the mechanical properties only slightly. When considering all stress-compression curves, it should be noted that no clear stress plateaus can be identified. However, shape memory effects are already known from the literature for the ternary system NiTiHf [27-29]. When examining literature results, it can also be seen that no clear plateaus need to occur in compression tests, and an SME can occur upon heating [17].

Since the materials did not show significant plateaus, the change in slope of the stress-compression curves suggests that a change in deformation mechanisms occurs [26]. Martensitic NiTi SMAs show stress/strain plateaus during loading which are related to detwinning, i.e. a growth of preferentially oriented martensite variants. Due to the wellknown stress/strain asymmetry [29, 30], these plateaus appear less well developed for compression testing. This indicates that detwinning processes are hampered and thus other elemental deformation processes take over during mechanical loading. This is probably related to the large monoclinic angles (Table 2) of $\mathrm{B} 19^{\prime}$ as they significantly affect twin boundary mobility [31].

Looking at $\mathrm{d} \sigma / \mathrm{d} \varepsilon$ in Fig. 3, the Tern, Quat and Co10sen, the $\mathrm{d} \sigma / \mathrm{d} \varepsilon$ decreases from a high initial value to form an elongated plateau and decreases strongly before final fracture. The plateau which forms could be an indication of lattice transformations or detwinning which is not clearly visible in the stress-strain curves. In the following functional tests, it will therefore be analyzed to what extent the plateaus can be linked to the processes of detwinning.

Furthermore, there is a strong difference in the $\mathrm{d} \sigma / \mathrm{d} \varepsilon$ curves of Co10sen and Co12sen. It is necessary to check to what extent this behavior depends on the test temperature and thus on the respective material condition, i.e. martensitic or austenitic.

As one of the main properties of a shape memory alloy the superelasticity (SE) was analyzed. For SE, the material has to be capable of forming stress-induced martensite in the austenitic state. Co12Sen and Co10Sen were investigated on the basis of the findings on mechanical properties. This should allow the investigation of differences in material behavior with respect to the test temperature and stoichiometry isolated from the effect of the number of elements.

The stress-compression curves of the senary alloy Co10Sen do not show clear plateaus under any of the temperatures employed (Fig. 4), so that SE could not be clearly observed. According to the classical assumption for 
SE to occur, the test temperature of the material must be above $A_{\mathrm{f}}$ and below the critical temperature for martensite deformation $M_{\mathrm{d}}$ [30, 32]. For Co10Sen $A_{\mathrm{f}}$ is approx. $210{ }^{\circ} \mathrm{C}$ (see Table 3) so that the investigations at $225^{\circ} \mathrm{C}$ and $250{ }^{\circ} \mathrm{C}$ should show plateaus if the alloy featured a SE. Although other studies already showed that distinct plateaus are not necessary for pseudoplastic behavior of SMAs [17], those findings are not necessarily transferable to SE of HEAs. Without plateaus or changes in slope it is not possible to distinguish between purely elastic behavior and possible detwinning of the material.

Characteristic values from the stress-compression curves at the respective temperatures are presented in Fig. 5. A comparison of the as-cast and heat-treated condition of Co10Sen and Co12Sen shows that the UCS as well as the compression at fracture were increased by the heat treatment. This is particularly evident in the case of Co12Sen in the tests carried out at $50{ }^{\circ} \mathrm{C}$, where the UCS of the heattreated samples is $170 \mathrm{MPa}$ higher and the fracture upsetting $7.8 \%$ higher than in the as-cast state. For Co10Sen the heat-treated state features an UCS that is $60 \mathrm{MPa}$ and a compression at fracture that is $4 \%$ higher than the as-cast condition for temperatures up to $155^{\circ} \mathrm{C}$. However, the heat treatment of Co10Sen did not have a positive effect on the UCS for $170-250{ }^{\circ} \mathrm{C}$.

It could be shown further that for both materials there seems to be a characteristic drop in the UCS and the compression at fracture from the purely martensitic state to the purely austenitic state. For Co12Sen this drop is above $A_{\mathrm{f}}$ while the drop for Co10Sen, which is just above $M_{\mathrm{s}}$ and well below $A_{\mathrm{f}}$, is much steeper. Since the samples do not show any significant plateaus above $M_{\mathrm{s}}$ and the stresscompression curves increasingly indicate an almost purely elastic behavior with increasing test temperature, superelasticity cannot be detected there.
Table 3 Transformation temperature determined by DSC in K

\begin{tabular}{lllll}
\hline Alloy & $M_{\mathrm{s}}$ & $M_{\mathrm{f}}$ & $A_{\mathrm{s}}$ & $A_{\mathrm{f}}$ \\
\hline Tern & 681 & 661 & 696 & 706 \\
Quat & 274 & 263 & 294 & 322 \\
Quin & 458 & 407 & 460 & 504 \\
Co10Sen & 429 & 373 & 423 & 488 \\
Co12Sen & 262 & 211 & 237 & 319 \\
\hline
\end{tabular}

From the literature, a schematic model is known which combines the thermodynamic Clausius-Clapeyron relationship with the critical energy required for slip [30]. It shows the regions of shape memory effects and superelasticity in temperature-stress coordinates [30]. If we can consider the critical stress for gliding to be proportional to the UCS [26], the measurement results of Co10Sen from Fig. 5 can be interpreted as illustrated as in Fig. 6 .

On the basis of the measured values, two different UCS levels are present, which, depending on the test temperature, correspond to martensitic $\left(\sigma_{\max },(\mathrm{M})\right)$ and austenitic $\left(\sigma_{\max , \text { (A) })}\right)$ behavior. Since, as described above, no superelasticity occurred above $170{ }^{\circ} \mathrm{C}$ two explanations seem plausible. Either the stress applied for forming induced martensite is higher than the stress required for sliding or superelasticity no longer occurs in this material above $170{ }^{\circ} \mathrm{C}$. If this is the case, there is a limit for stressinduced martensite $\left(\sigma_{\text {sim }}\right)$ and with it the area in which superelasticity could possibly occur (gray), is very narrow. The steep drop in the UCS in Fig. 6 is also an indication that the applied stress only has a minimal influence on the transformation behavior of the lattice. A possible explanation for this is the already highly distorted lattice in the senary state [25], which probably cannot be transformed by external stresses but only by temperature.
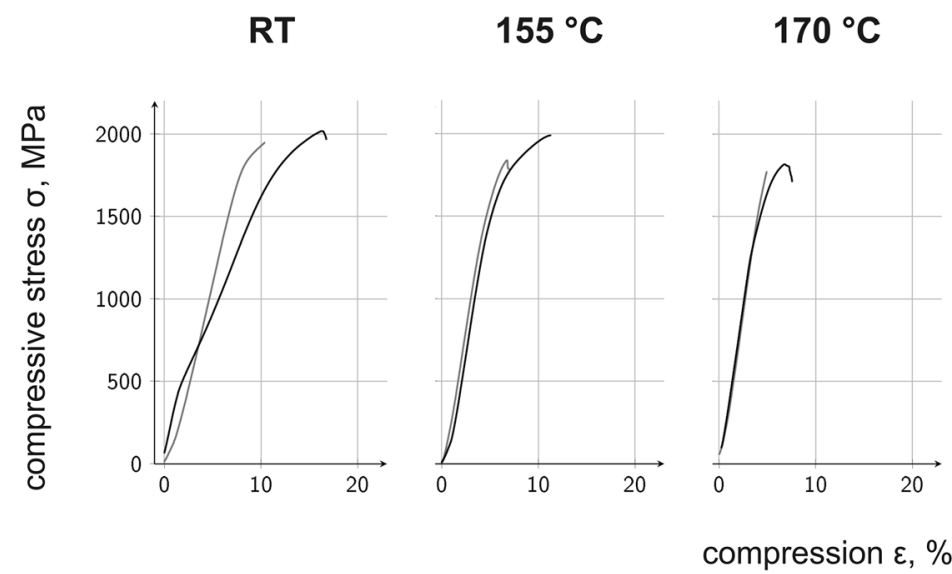

$225^{\circ} \mathrm{C}$

$250^{\circ} \mathrm{C}$

$$
\text { compression } \varepsilon, \%
$$
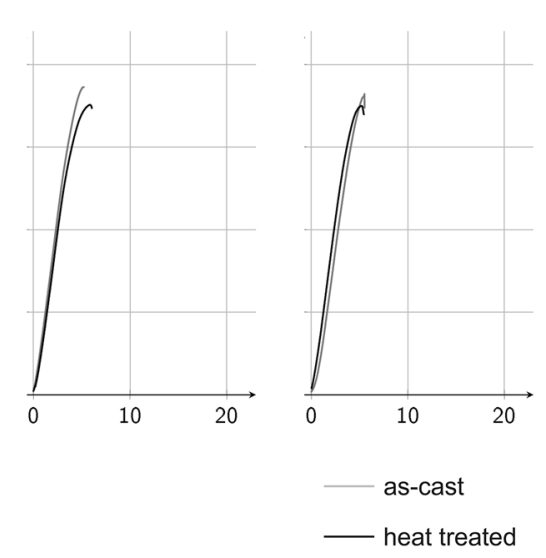

Fig. 4 Stress-compression curves of Co10Sen for different temperatures in as-cast and in heat-treated conditions 
Co12Sen
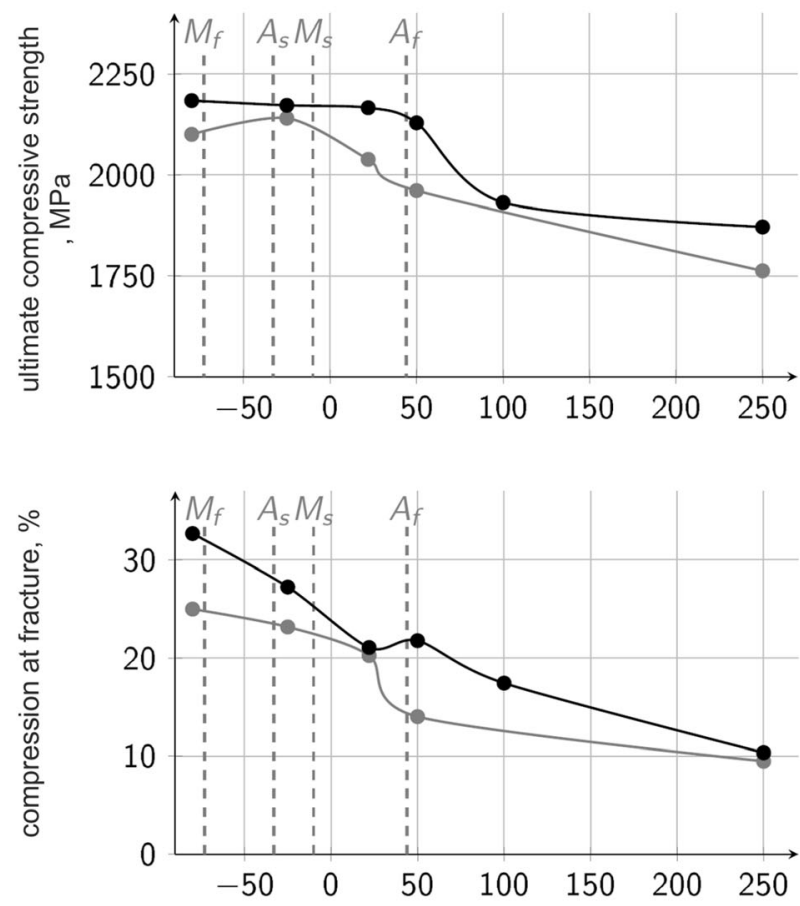

Co10sen
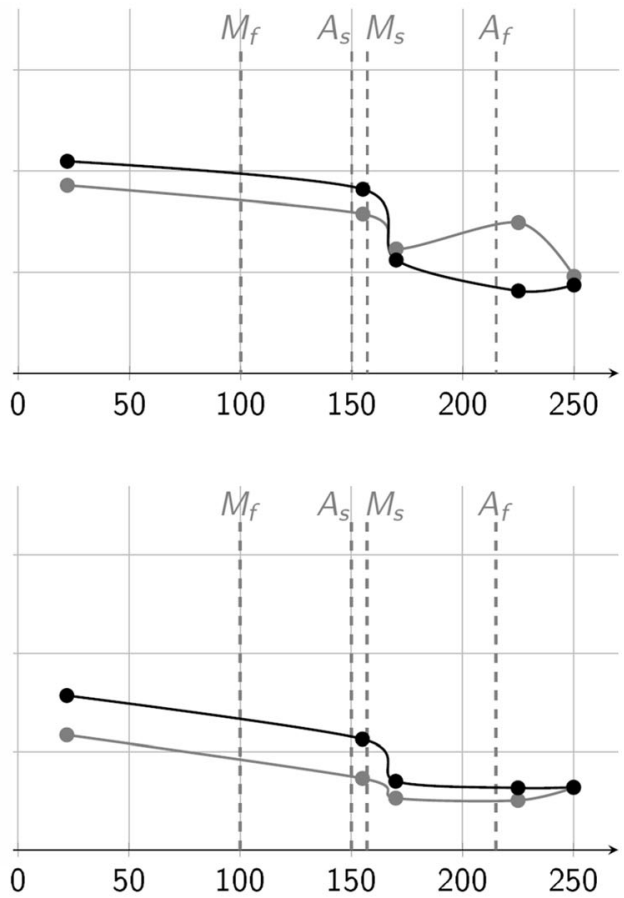

temperature, ${ }^{\circ} \mathrm{C}$

- as-cast

- heat-treated

Fig. 5 Ultimate compressive strength and compression at fracture vs temperature for Co12Sen and Co10Sen in as-cast and in heat-treated state ( $M_{\mathrm{s} / \mathrm{f}}$ and $A_{\mathrm{s} / \mathrm{f}}$ from DSC-measurements see Table 3)

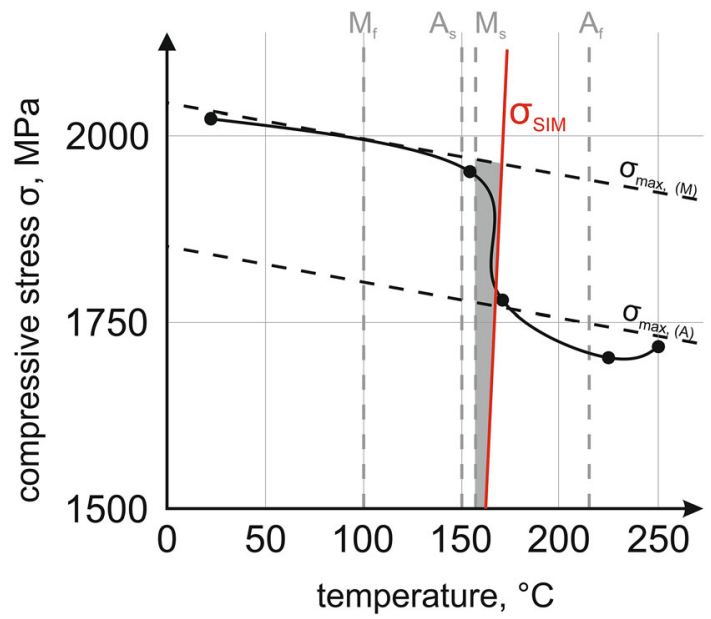

Fig. 6 Stress-temperature relationship of Co10Sen; following Otsuka et al. [30], the sharp transition between the ultimate compressive strength levels for austenite $\left(\sigma_{\max }\right.$, (A) $)$ and martensite $\left(\sigma_{\max }\right.$, (M) result in a nearly vertical line for possible stress-induced martensite $\left(\sigma_{\text {sim }}\right)$ and therefore a small area where superelasticity effects could occur (gray) (Color figure online)

\section{Shape Recovery}

For analyzing the shape recovery, the cylindrical samples were mechanically compressed at a cross-head speed of $1 \mu \mathrm{m} / \mathrm{s}$ to a given stress value and then the compressive stress was relieved. The stress values of the cycles were determined from the previously established stress-compression curves, which show possible detwinning processes during deformation as indicated by the changes in $\mathrm{d} \sigma / \mathrm{d} \varepsilon$. The stress-compression-hysteresis of the specimen were recorded since the shape of the hysteresis provides decisive information about the degradation behavior of the material. After each cycle the samples were heated above $A_{\mathrm{f}}$ outside the testing machine and the absolute dimensions of the samples before and after heating were measured to determine compression recovery.

Figure 7 shows the results of the analysis of the shape recovery for the Tern and Quin alloy. These alloys were selected because they are in the martensitic state at room temperature and do not have to be cooled before the compression test. The compression curves in Fig. 7a were employed to determine the stresses to be used in the cyclic tests. The resulting hysteresis reported in Fig. $7 \mathrm{~b}$ were measured based on cross-head displacement. The absolute 
Fig. 7 Comparison of the oneway shape memory effect of Tern and Quin samples, a stress-strain curves from compression tests with marked stress levels for $\mathbf{b}$ cyclic testing, and $\mathbf{c}$ fatigue behavior determined by the accumulation of residual strains over functional cycles

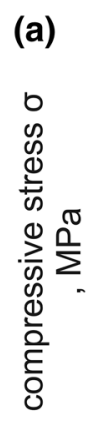

Tern

Quin
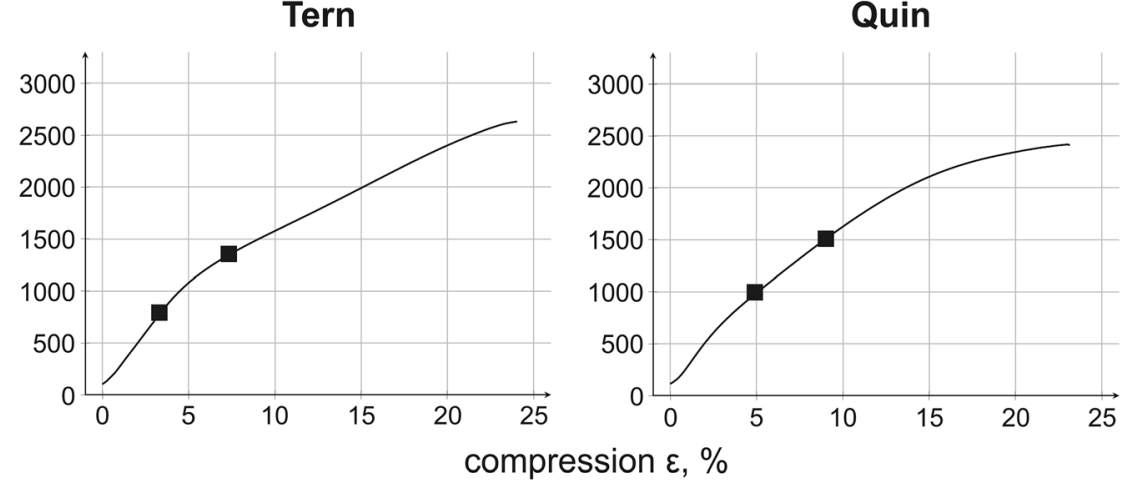

(b)

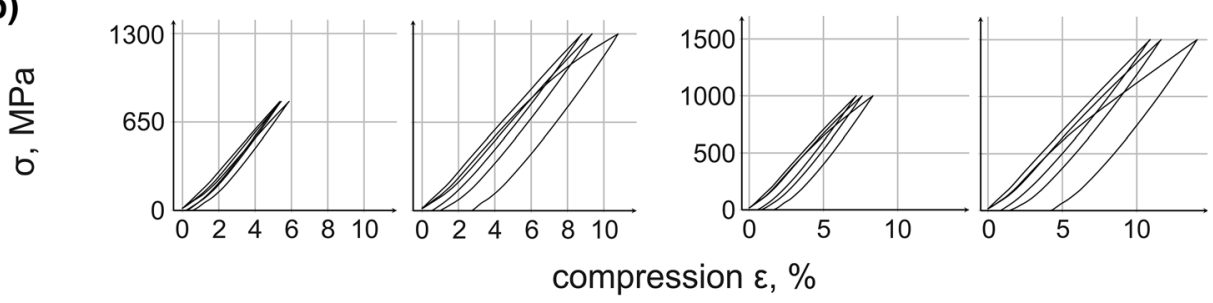

(c)

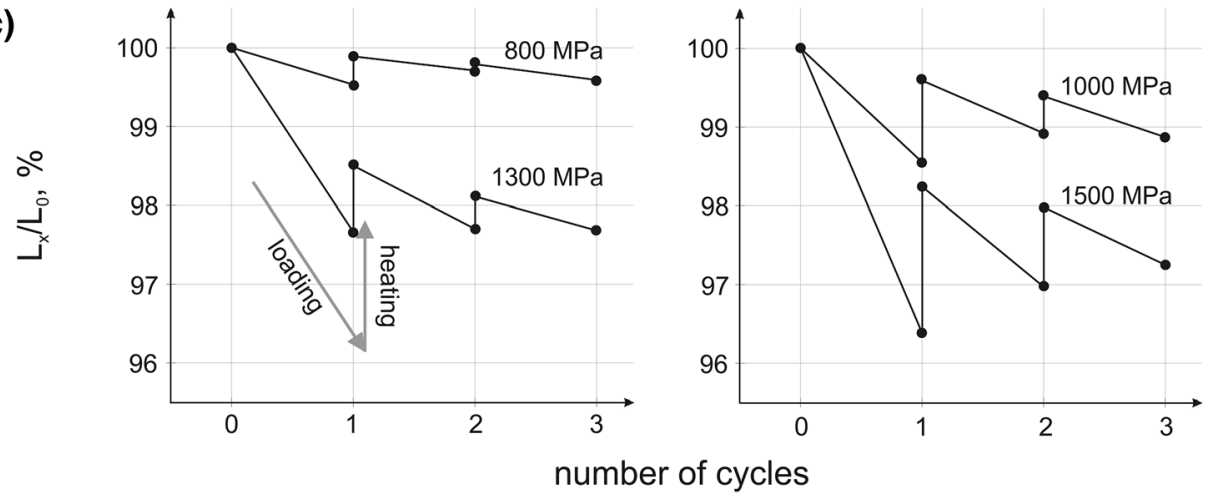

values of the sample length for each shape memory cycle are shown in Fig. 7c.

\section{Ternary SMA}

For the Tern alloy in the heat-treated condition, $-800 \mathrm{MPa}$ and $-1300 \mathrm{MPa}$ were defined as stress values for cyclic testing. Cyclic tests below $-800 \mathrm{MPa}$ showed purely elastic deformation and were therefore not suitable for shape recovery investigations. The Tern specimens were heated to $500{ }^{\circ} \mathrm{C}$ in inert gas atmosphere after each compression cycle.

During the first cycle, the specimen compressed at $-800 \mathrm{MPa}$ was initially shortened by only $0.5 \%$ and then recovered $0.4 \%$ of its original length after heating. The heating was thus able to restore about $80 \%$ of the deformation. Statements about the subsequent cycles cannot be made reliably due to the extremely small deformation and the resulting uncertainties in strain measurement. It can be concluded that the shape memory effect is not pronounced at $-800 \mathrm{MPa}$, as this stress is probably not sufficient to detwin the martensite.

In the cyclic tests with $-1300 \mathrm{MPa}$, the curves of the hysteresis show a gradual decrease in the change in slope with each cycle. In the first cycle, the specimen was compressed by $2.4 \%$ and was recovered $1.0 \%$ of the original length upon heating. Subsequent cycles compressed the sample to the same height, but the recovery was significantly reduced.

\section{Quinary SMA}

For the Quin alloy in the heat-treated state, $-1000 \mathrm{MPa}$ and $-1500 \mathrm{MPa}$ were defined as stress values. Cyclic tests below $-500 \mathrm{MPa}$ showed purely elastic deformation and were therefore not suitable for shape recovery investigations. The Quin specimens were heated to $300{ }^{\circ} \mathrm{C}$ after each compression cycle.

During the first cycle, the specimen cycled up to $-1000 \mathrm{MPa}$ was upset by $1.5 \%$ and recovered $1.1 \%$ of its 
original length upon heating. The re-heating thus restored more than $73 \%$ of the initially introduced deformation.

For cyclic tests up to $-1500 \mathrm{MPa}$, the specimen was upset by $2.6 \%$ in the first cycle and after heating $1.9 \%$ of the initial length was restored. Subsequent cycles led to the same specimen height after heating, but with the same compressive stress the specimen height increased after loading. The behavior therefore shows a hardening of the material per cycle and at the same time a return to a constant initial length.

The comparison of functional properties during the increase of chemical complexity shows some clear trends. It is remarkable that the ternary and quinary alloys showed recoveries in a tests at $-1000 \mathrm{MPa}$ and $-1500 \mathrm{MPa}$. Although there is a decrease in the shape recovery over the cycles, this is a two to three times higher load then that typically employed for the conventionally used NiTi $[30,32]$. The shape recovery at compressive stresses above $-1000 \mathrm{MPa}$ shows the enormous potential of HESMAs.

\section{Conclusion}

In the present study different shape memory alloys ranging from ternary to senary were developed to exploit the highentropy concept. Starting from the NiTi system, it could be shown how the successive increase in chemical complexity results in strictly monotonically enlarged and increasingly distorted lattices.

Mechanical testing showed that the ultimate compressive strength and the compression at fracture decreases with increase in chemical complexity. A heat treatment of the material tends to increase both compressive strength and compression at fracture. However, the difference between the as-cast and the heat-treated condition increases significantly with increasing number of elements in the alloy. This indicates an increased inhomogeneity or the existence of multiple phases with successive increase in chemical complexity, so that an appropriate heat treatment is necessary. Pronounced solid solution strengthening resulting from an increase in the number of elements could not be observed.

Although the complexity of compositions does not result in a direct improvement of mechanical and functional properties, the alloys developed show great potential in the context of functional fatigue. Despite the absence of conventional stress plateaus, shape memory effects at compressive loads above $1000 \mathrm{MPa}$ and recoverable strains of more than $1 \%$ could be found.

Acknowledgements This study was funded by the Deutsche Forschungsgemeinschaft (DFG, German Research Foundation) within
Grants \#388671975 and 313773923. The authors also thank G. S. Firstov for discussions on the topic.

\section{Appendix}

See Fig. 8.

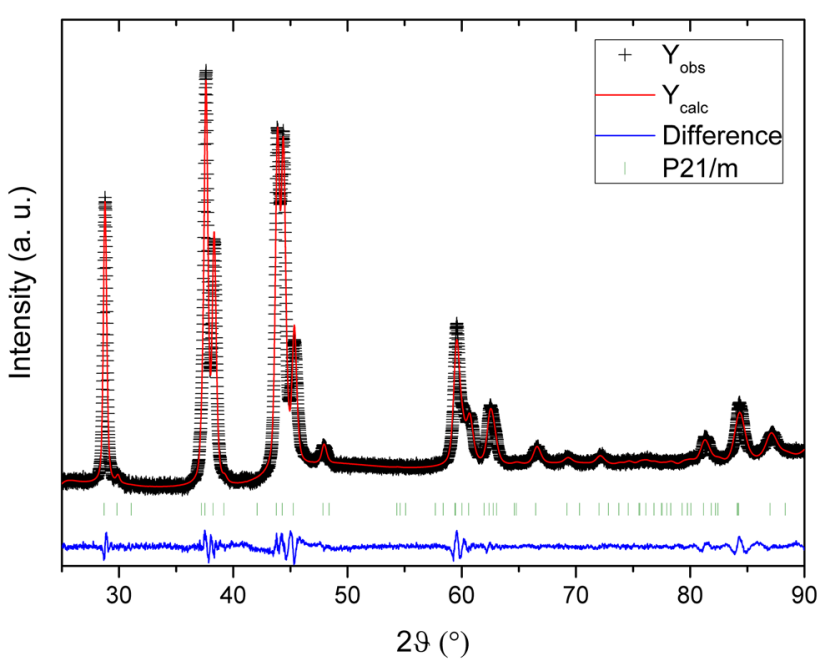

Fig. $8 \mathrm{X}$-ray diffractograms of $\mathrm{Ni}_{50} \mathrm{Ti}_{25} \mathrm{Hf}_{25}$ : experimental data collected at room temperature (black ' + ' markers), calculated data (red line), and difference of the two (blue line) as a function of the diffraction angle $2 \theta$; indexing of the reflections according to space group used for fitting, $\mathrm{P} 21 / \mathrm{m}$, are also shown in green tickmarks (Color figure online)

\section{References}

1. Ma J, Karaman I, Noebe RD (2013) High temperature shape memory alloys. Int Mater Rev. https://doi.org/10.1179/ $095066010 X 12646898728363$

2. Pappas P, Bollas D, Parthenios J, Dracopoulus V, Galiotis C (2007) Transformation fatigue and stress relaxation of shape memory alloy wires. Smart Mater Struct. https://doi.org/10.1088/ 0964-1726/16/6/060

3. Pelton AR (2011) Nitinol fatigue: a review of microstructures and mechanisms. J Mater Eng Perform. https://doi.org/10.1007/ s11665-011-9864-9

4. Firstov GS, Kosorukova TA, Koval YN, Odnosum VV (2015) High entropy shape memory alloys. Mater Today Proc. https:// doi.org/10.1016/j.matpr.2015.07.335

5. Firstov GS, Kosorukova TA, Koval YN, Verhovlyuk PA (2015) Directions for high-temperature shape memory alloys' improvement: straight way to high-entropy materials? Shap Mem Superelast. https://doi.org/10.1007/s40830-015-0039-7

6. Murty BS, Yeh J-W, Ranganathan S (2014) High-entropy alloys, 1 st edn. Butterworth-Heinemann, Amsterdam

7. Miracle DB, Senkov ON (2017) A critical review of high entropy alloys and related concepts. Acta Mater. https://doi.org/10.1016/j. actamat.2016.08.081

8. George EP, Curtin WA, Tasan CC (2020) High entropy alloys: a focused review of mechanical properties and deformation mechanisms. Acta Mater. https://doi.org/10.1016/j.actamat.2019.12.015 
9. Yeh J-W, Chen S-K, Lin S-J, Gan J-Y, Chin T-S, Shun T-T, Tsau C-H, Chang SY (2004) Nanostructured high-entropy alloys with multiple principal elements: novel alloy design concepts and outcomes. Adv Eng Mater. https://doi.org/10.1002/adem.200300567

10. Cantor B, Chang ITH, Knight P, Vincent AJB (2004) Microstructural development in equiatomic multicomponent alloys. Mat Sci Eng A. https://doi.org/10.1016/j.msea.2003.10. 257

11. Senkov ON, Scott JM, Senkova SV, Miracle DB, Woodward CF (2011) Microstructure and room temperature properties of a highentropy TaNbHfZrTi alloy. J Alloys Compd. https://doi.org/10. 1016/j.jallcom.2011.02.171

12. George EP, Raabe D, Ritchie RO (2019) High-entropy alloys. Nat Rev Mater. https://doi.org/10.1038/s41578-019-0121-4

13. Canadinc D, Trehern W, Ma J, Karaman I, Sun F, Chaudhry Z (2019) Ultra-high temperature multi-component shape memory alloys. Scripta Mater. https://doi.org/10.1016/j.scriptamat.2018. 08.019

14. Chen C-H, Chen Y-J (2019) Shape memory characteristics of (TiZrHf) ${ }_{50} \mathrm{Ni}_{25} \mathrm{Co}_{10} \mathrm{Cu}_{15}$ high entropy shape memory alloy. Scripta Mater. https://doi.org/10.1016/j.scriptamat.2018.11.023

15. Chumlyakov Y, Kireeva I, Panchenko E, Karaman I, Maier HJ, Timofeeva E (2013) Shape memory effect and high-temperature superelasticity in high-strength single crystals. J Alloys Compd. https://doi.org/10.1016/j.jallcom.2012.02.003

16. Kuksgauzen I, Kireeva I, Chumlyakov Y, Maier HJ (2017) Oneway and two-way shape memory effect in single-phase CoNiGa single crystals. Mater Today Proc. https://doi.org/10.1016/j. matpr.2017.04.071

17. Benafan O, Garg A, Noebe RD, Bigelow GS, Padula SA II, Gaydosh DJ, Schell N, Mabe JH, Vaidyanathan R (2014) Mechanical and functional behavior of a Ni-rich Ni50.3Ti29.7Hf20 high temperature shape memory alloy. Intermetallics. https://doi.org/10.1016/j.intermet.2014.02.006

18. Le Bail A, Duroy H, Fourquet JL (1988) Ab-initio structure determination of $\mathrm{LiSbWO}_{6}$ by X-ray powder diffraction. Mater Res Bull. https://doi.org/10.1016/0025-5408(88)90019-0

19. Le Bail A (2005) Whole powder pattern decomposition methods and applications: a retrospection. Powder Diffr. https://doi.org/ $10.1154 / 1.2135315$

20. Coelho AA (2018) TOPAS and TOPAS-Academic: an optimization program integrating computer algebra and crystallographic objects written in C++. J Appl Crystallogr. https://doi. org/10.1107/S1600576718000183

21. Piorunek D, Frenzel J, Jöns N, Somsen C, Eggeler G (2020) Chemical complexity, microstructure and martensitic transformation in high entropy shape memory alloys. Intermetallics. https://doi.org/10.1016/j.intermet.2020.106792

22. Greenwood NN, Earnshaw A (2012) Chemistry of the elements, 2nd edn. Pergamon Press, Oxford

23. Frenzel J, George EP, Dlouhy A, Somsen Ch, Wagner MF-X, Eggeler G (2010) Influence of $\mathrm{Ni}$ on martensitic phase transformations in NiTi shape memory alloys. Acta Mater. https://doi. org/10.1016/j.actamat.2010.02.019

24. Frenzel J, Wieczorek A, Opahle I, Maaß B, Drautz R, Eggeler G (2015) On the effect of alloy composition on martensite start temperatures and latent heats in $\mathrm{Ni}$-Ti-based shape memory alloys. Acta Mater. https://doi.org/10.1016/j.actamat.2015.02.029

25. Firstov GS, Timoshevski A, Kosorukova TA, Koval YN, Matviychuk Y, Verhovlyuk PA (2015) Electronic and crystal structure of the high entropy TiZrHfCoNiCu intermetallics undergoing martensitic transformation. Matec Web Conf. https:// doi.org/10.1051/matecconf/20153306006

26. Gottstein G (2007) Physikalische Grundlagen der Materialkunde (physical basics of materials science), 3rd edn. Springer, Heidelberg

27. Firstov GS, Van Humbeeck J, Koval YN (2004) Comparison of high temperature shape memory behavior for $\mathrm{ZrCu}$-based, Ti$\mathrm{Ni}-\mathrm{Zr}$ and Ti-Ni-Hf alloys. Scripta Mater. https://doi.org/10. 1016/j.scriptamat.2003.09.010

28. Firstov GS, Van Humbeeck J, Koval YN (2004) High-temperature shape memory alloys Some recent developments. Mater Sci Eng A. https://doi.org/10.1016/j.msea.2003.10.324

29. Karaca HE, Acar E, Tobe H, Saghaian SM (2014) NiTiHf-based shape memory alloys. Mater Sci Technol. https://doi.org/10.1179/ 1743284714Y.0000000598

30. Otsuka K, Wayman CM (1999) Shape memory materials. Cambridge University Press, Cambridge

31. Laplanche G, Birk T, Schneider S, Frenzel J, Eggeler G (2017) Effect of temperature and texture on the reorientation of martensite variants in NiTi shape memory alloys. Acta Mater. https://doi.org/10.1016/j.actamat.2017.01.023

32. Stöckel D, Hornbogen E, Ritter F, Tautzenberger P (1988) Legierungen mit Formgedächtnis: Industrielle Nutzung des Shape-Memory-Effektes (Alloys with shape memory: Industrial use of the shape memory effect). GDMB, Clausthal-Zellerfeld

Publisher's Note Springer Nature remains neutral with regard to jurisdictional claims in published maps and institutional affiliations. 